\title{
Benefits of Multi-Professional Rehabilitation of Patients with Advanced Cancer
}

\author{
Salakari MRJ ${ }^{1^{*}}$, Surakka Tiina ${ }^{2}$, Nurminen Raija ${ }^{3}$ and Pylkkänen Liisa ${ }^{4}$ \\ ${ }^{1}$ Department of Public Health, University of Turku, Finland \\ ${ }^{2}$ Cancer Society of Southwest Finland, Finland \\ ${ }^{3}$ Turku University of Applied Sciences, Turku, Finland \\ ${ }^{4}$ Cancer Society of Finland, Finland
}

"Corresponding author: Salakari MRJ, Master of Health Care, University of Turku, Department of Public Health, Rykmentintie 43 , FI-20880 Turku, Finland, Tel: +358 4073078 77; E-mail: minna.salakari@luukku.com

Received date: May 25, 2015; Accepted date: Jul 10, 2015; Published date: Jul 15, 2015

Copyright: @2015 Salakari MRJ. This is an open-access article distributed under the terms of the Creative Commons Attribution License, which permits unrestricted use, distribution, and reproduction in any medium, provided the original author and source are credited.

\section{Summary}

The overall incidence and prevalence of cancer increases, and patients today live longer with advanced cancer than in previous decades [1]. Many patients with advanced cancer have significant long-term disabilities and require continuous care and support [2]. The symptoms and disabilities may be related to the cancer itself but to the treatments, as well $[3,4]$. Functional impairment is often accompanied with significant psychosocial morbidity [1].

Prevention and management of pain, fatigue, deconditioning, depression, anxiety, functional impairment, cognitive decline, and peripheral neuropathy appear to be the most effective measures to prolong the active life expectancy especially of elderly patients with advanced cancer [5].

Timely rehabilitation may ensure better functional capacity for patients with advanced cancer, maintain the quality of life (QoL), and improve independence [2]. It may also save the health care costs [6]. Studies emphasize the need for rehabilitation in this patient group, but, at the same time, acknowledge that rehabilitation is underused [2]. This may be due to a lack of information about the benefits of rehabilitation, lack of referrals by oncologists, or lack of resources [1].

Recently we published a systematic review based on randomized controlled trials (RCTs) on the effects of rehabilitation among patients with advanced cancer [7]. The aim of the review was to summarize what is known about rehabilitation of patients with advanced cancer, what kind of rehabilitation is available and what type of additional research is needed.

Seven of the 13 randomized controlled trials published between January 2009 and August 2014 were based on physical exercise intervention [8-14], two [15,16] on self-management rehabilitation, and one each on cost-effectiveness [6], swallowing rehabilitation [17], cognitive-behavioral intervention [18], and psycho-education [19]. Most studies included patients with various diagnoses of advanced cancer, but breast and prostate cancers and hematological malignancies were the most common cancers included.

The review indicated that multi-professional rehabilitation is needed also for patients living with advanced disease, including patients in palliative care (Figure 1). No adverse effects related to rehabilitation were identified. All studies reported positive findings, but there may, however, be a reporting bias (i.e., only positive studies may have been published).

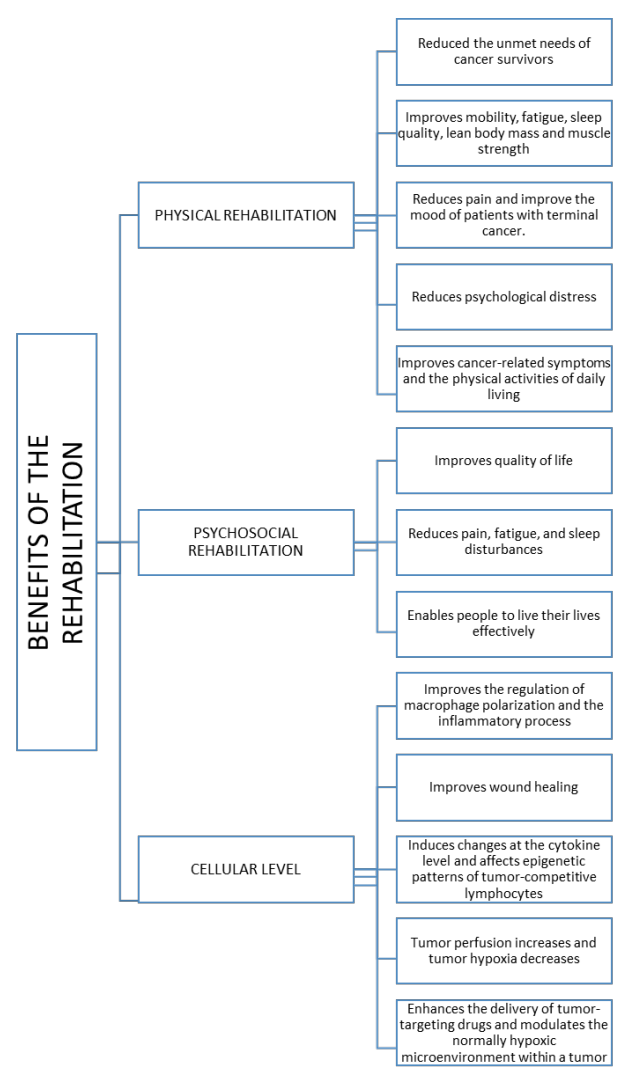

Figure 1: The benefits of the rehabilitation

Based on our systematic review, effective multi-professional rehabilitation appear to improve the overall QoL of the patients. Physical rehabilitation improves physical performance and has positive effects on several other QoL domains. Psychosocial rehabilitation (including self-management programs and cognitivebehavioral interventions) improves QoL, reduces pain, fatigue, and sleep disturbances $[15,18]$, and enables people with chronic cancer to live their lives effectively [15]. Rehabilitation reduces the unmet needs of cancer survivors and is cost-effective [6].

Concerning the possible mechanisms of action at the cellular level, exercise can improve the regulation of macrophage polarization and the inflammatory process, and improve wound healing in older people with cancer [20] Exercise also induces changes at the cytokine level 
and affects epigenetic patterns and activity of tumor-competitive lymphocytes [21] During exercise, tumor perfusion increases and tumor hypoxia decreases, which reduces vasoconstriction. Exercise may also enhance the delivery of tumor-targeting drugs and modulate the normally hypoxic microenvironment within a tumor and thus lead to a less aggressive phenotype [22]. All these mechanism are of outmost importance also for patients with advanced cancer.

In parallel with the rising number of patients living with advanced disease it is essential to develop and maintain rehabilitation services also for this patient group. The rehabilitation goals are variable and individual in this group of cancer patients. The aim of rehabilitation should be to help the patient to live a rich and satisfying life irrespective of all disabilities, and to help the patient to live as independently and productively as possible $[2,23]$. The aim should also be to minimize the adverse consequences of treatment, and to support psychosocial adaptation. The role of relatives, caregivers, and friends is significant, in particular in the palliative stage of the disease [23,24]. These actors need also support and rehabilitation, which is often forgotten.

In this patient group we should consider rehabilitation outside of the facility - also home-based exercise programs seem to improve mobility, reduce fatigue, and improve sleep quality of patients with advanced cancer [10]. Cancer rehabilitation in this patient group should be multi-professional and multi-faceted and it should focus on supporting the overall well-being of patients according to the individual patient's condition and needs. If the rehabilitation needs are not clearly identified, patients will receive only suboptimal help when they try to cope with their disabilities. Due to progressive nature of advanced cancer, the goals of rehabilitation need to be assessed frequently and the rehabilitation targets need to be reset accordingly.

It is important to empower the patients themselves, and the role of health care professionals is to support the self-care. Rehabilitation is to work with the patient, not for the patient [25]. Further studies are needed to establish which kind of rehabilitation best alleviates pain and fatigue and supports the independence and QoL among these patients. More data are also needed on cost-effectiveness and on the possible adverse effects of rehabilitation.

In conclusion, findings suggest that multi-professional rehabilitation is needed for patients with advanced cancer, also in palliative care. Rehabilitation has been found to improve physical performance and has positive effects on several domains of QoL, but more research would be required. The challenge for the future is to design rehabilitation based on the cancer patient's individual needs. Assessment of the needs and appropriate assessment tools are also needed.

\section{References}

1. Cheville A (2001) Rehabilitation of patients with advanced cancer. Cancer Supplement: Cancer Rehabilitation in the New Millennium 92: 1039-1048.

2. Silver JK, Baima J, Mayer RS (2013) Impairment-driven cancer rehabilitation: an essential component of quality care and survivorship. CA Cancer J Clin 63: 295-317.

3. Payne C, Wiffen PJ, Martin S (2012) Interventions for fatigue and weight loss in adults with advanced progressive illness. Cochrane Database Syst Rev 1: CD008427.

4. Cavalheri V, Tahirah F, Nonoyama M, Jenkins S, Hill K (2013) Exercise training undertaken by people within 12 months of lung resection for non-small cell lung cancer. Cochrane Database Syst Rev 7: CD009955.
5. Gupta AD, Lewis S, Shute R (2010) Patients living with cancer - the role of rehabilitation. Aust Fam Physician 39: 844-846.

6. Jones L, Fitzgerald G, Leurent B, Round J, Eades J, et al. (2013) Rehabilitation in advanced, progressive, recurrent cancer: a randomized controlled trial. J Pain Symptom Manage 46: 315-325.

7. Salakari MR, Surakka T, Nurminen R, Pylkkänen L (2015) Effects of rehabilitation among patients with advances cancer: a systematic review. Acta Oncol 54: 618-628.

8. Oldervoll LM1, Loge JH, Lydersen S, Paltiel H, Asp MB, et al. (2011) Physical exercise for cancer patients with advanced disease: a randomized controlled trial. Oncologist 16: 1649-1657.

9. Litterini AJ, Fieler VK, Cavanaugh JT, Lee JQ (2013) Differential effects of cardiovascular and resistance exercise on functional mobility in individuals with advanced cancer: a randomized trial. Arch Phys Med Rehabil 94: 2329-2335.

10. Cheville AL, Kollasch J, Vandenberg J, Shen T, Grothey A, et al. (2013) A home-based exercise program to improve function, fatigue, and sleep quality in patients with Stage IV lung and colorectal cancer: a randomized controlled trial. J Pain Symptom Manage 45: 811-821.

11. López-Sendín N, Alburquerque-Sendín F, Cleland JA, Fernández-de-lasPeñas C (2012) Effects of physical therapy on pain and mood in patients with terminal cancer: a pilot randomized clinical trial. See comment in PubMed Commons below J Altern Complement Med 18: 480-486.

12. Cheville AL, Girardi J, Clark MM, Rummans TA, Pittelkow T, et al. (2010) Therapeutic exercise during outpatient radiation therapy for advanced cancer: Feasibility and impact on physical well-being. Am J Phys Med Rehabil 89: 611-619.

13. Uth J, Hornstrup T, Schmidt JF, Christensen JF, Frandsen C, et al. (2014) Football training improves lean body mass in men with prostate cancer undergoing androgen deprivation therapy. Scand J Med Sci Sports 24: 105-112.

14. Jensen W, Baumann FT, Stein A, Bloch W, Bokemeyer C, et al. (2014) Exercise training in patients with advanced gastrointestinal cancer undergoing palliative chemotherapy: a pilot study. Care Cancer 22: 1797-1806.

15. Loh SY, Packer T, Chinna K, Quek KF (2013) Effectiveness of a patient self-management programme for breast cancer as a chronic illness: a non-randomised controlled clinical trial. J Cancer Surviv 7: 331-342.

16. Gaston-Johansson F, Fall-Dickson JM, Nanda JP, Sarenmalm EK, Browall M, et al. (2013) Long-term effect of the self-management comprehensive coping strategy program on quality of life in patients with breast cancer treated with high-dose chemotherapy. Psychooncology 22: 530-539.

17. van der Molen L, van Rossum MA, Rasch CR, Smeele LE, Hilgers FJ (2014) Two-year results of a prospective preventive swallowing rehabilitation trial in patients treated with chemoradiation for advanced head and neck cancer. Eur Arch Otorhinolaryngol 271: 1257-1270.

18. Kwekkeboom KL, Abbott-Anderson K, Cherwin C, Roiland R, Serlin RC, et al. (2012) Pilot randomized controlled trial of a patient-controlled cognitive-behavioral intervention for the pain, fatigue, and sleep disturbance symptom cluster in cancer. J Pain Symptom Manage 44: 810-822.

19. Chan CW, Richardson A, Richardson J (2011) Managing symptoms in patients with advanced lung cancer during radiotherapy: results of a psychoeducational randomized controlled trial. J Pain Symptom Manage 41: 347-357.

20. Goh J, Ladiges WC (2014) Exercise enhances wound healing and prevents cancer progression during aging by targeting macrophage polarity. Mech Ageing Dev 139: 41-48.

21. Zimmer P, Baumann FT, Bloch W, Schenk A, Koliamitra C, et al. (2014) Impact of exercise on pro inflammatory cytokine levels and epigenetic modulations of tumor-competitive lymphocytes in Non-HodgkinLymphoma patients-randomized controlled trial. Eur J Haematol. 93: $527-532$

22. McCullough DJ, Stabley JN, Siemann DW, Behnke BJ (2014) Modulation of blood flow, hypoxia, and vascular function in orthotopic prostate 
Citation: Salakari MRJ, Tiina S, Raija N and Liisa P (2015) Benefits of Multi-Professional Rehabilitation of Patients with Advanced Cancer . J Carcinog Mutagen 6: 232. doi:10.4172/2157-2518.1000232

Page 3 of 3

tumors during exercise. in PubMed Commons below J Natl Cancer Inst 106: 036.

23. Tamagawa R, Garland S, Vaska M, Carlson LE (2012) Who benefits from psychosocial interventions in oncology? A systematic review of psychological moderators of treatment outcome. J Behav Med 35: 658-673.
24. Chochinov HM (2001) Depression in cancer patients. Lancet Oncol: 499-505.

25. Johnston B, McGill M, Milligan S, McElroy D, Foster C, et al. (2009) Self care and end of life care in advanced cancer: literature review. Eur J Oncol Nurs 13: 386-398. 